\title{
Saneamento E SAÚde INDíGenA: UMA AVALIAÇÃo NA população Xakriabá, Minas Gerais
}

\section{ENVIRONMENTAL SANITATION AND INDIAN HEALTH: AN ASSESSMENT ON THE Xakriabá population, Minas Gerais}

\begin{abstract}
JOÃO LUIZ PENA
Engenheiro civil, cientista social, mestre em saneamento, meio ambiente e recursos hídricos, consultor da Rede Nacional de Capacitação e Extensão Tecnológica em Saneamento Ambiental - ReCESA, Núcleo Sudeste

\section{LÉO HELLER}

Engenheiro civil, mestre em engenharia sanitária, doutor em epidemiologia, pós-doutorado em políticas públicas na University of Oxford, professor associado do Departamento de Engenharia Sanitária e Ambiental - UFMG
\end{abstract}

\section{Recebido: 14/05/07 Aceito: 25/01/08}

\section{RESUMO}

Avaliam-se as condições de saneamento, o quadro de saúde e a associação entre ambas as situaçōes, na população indígena Xakriabá. A avaliação verifica-se no contexto das intervençōes em saneamento realizadas pelas instituições responsáveis pela saúde indígena no Brasil. Para tanto, empregou-se um delineamento ecológico, tomando-se como unidade de análise 26 localidades, segundo as quais se organiza o setor biomédico. Verificou-se que, no período analisado pelo estudo - 2000 a 2002 -, apesar de a FUNASA estar atuando naquela Terra Indígena, as condições sanitárias dos Xakriabá não são satisfatórias, principalmente de suas crianças. Elevada prevalência de doenças endêmicas como a verminose, altas taxas de incidência de diarréia e doenças infecciosas de pele e más condições de saneamento faziam parte do cotidiano deste povo. Mesmo constatando a atuação limitada e, por vezes, deficiente do setor de saneamento na Terra Indígena, os resultados deste estudo parecem corroborar o estudo de Briscoe que indica serem os serviços de saneamento condições necessárias, porém não suficientes para promover a melhoria da saúde.

PALAVRAS-CHAVE: Saneamento, saúde ambiental, diarréia, Xakriabá, saúde indígena.

\begin{abstract}
The sanitary conditions, the health situation and the association between them were assessed on the Xakriaba population, looking at interventions by the institutions in charge of the Indian health in Brazil. An ecological design was used, adopting as unity of analysis 26 areas, according to the way the biomedical sector is organized in the indigenous land. It was verified that in the period of this study - 2000 to 2002 -, the sanitary Indian conditions had not improved, particularly concerning the children, although the FUNASA had been active in the Xakriaba Indian land. The presence of endemic problems such as parasitosis, high incidence of diarrhoea and skin infectious diseases was very common among these people. Even with limited and sometimes deficient action by the sanitary sector in the Indian land, the results of this study seem to reinforce Briscoe's hypothesis, that water supply and sanitation conditions are necessary but not sufficient conditions to improve health.
\end{abstract}

KEYWORDS: Sanitation, environmental health, diarrhea, Xakriabá, Indian health.

\section{INTRODUÇÃO}

No presente, é amplamente reconhecido que o saneamento, dentre as atividades de saúde pública, constitui um importante meio de prevenir doenças. Segundo a Organização Mundial de Saúde, saneamento é "o controle de todos os fatores de meio físico do homem que exercem ou podem exercer efeito deletério sobre o seu bem-estar físico, mental ou social” (Mota, 1999:405). Assim, o objeto do saneamento é a promoção da saúde do ser humano, bem como a promoção da melhoria da qualidade de vida das populaçôes.
São muitas as doenças que podem proliferar e se manter devido à falta ou inadequação de medidas de saneamento. Dentre os fatores que contribuem para uma maior incidência ou prevalência dessas doenças encontram-se a baixa disponibilidade de água, seu fornecimento com qualidade indevida, a inadequada disposição dos dejetos e um inadequado destino dos resíduos. De acordo com Briscoe, Feachem \& Rahaman (1986), os investimentos em saneamento possibilitam a redução da morbidade infantil por diarréia, desnutrição, parasitoses intestinais, doenças oculares e doenças da pele, entre outras.
Os Xakriabá, estudados na pesquisa, são habitantes de uma região historicamente denominada sertão, sertão mineiro ou sertão sanfranciscano, vivendo no município de São João das Missões, norte de Minas Gerais. Segundo Rodrigues (1975), a filiação lingüística do povo Xakriabá, cujo dialeto tem o mesmo nome, pertence ao tronco lingüístico Macro-Jê, família Jê, língua Akwên. Vale salientar que, hoje, os Xakriabá já não falam a língua original, usam o português regional. O território tradicional dos falantes da língua Akwên e dialetos dela derivados (xakriabá, xavante e xerente) abrangia 
uma faixa de terra que tinha como limites as bacias dos rios Araguaia, Tocantins e São Francisco, de Goiás ao Maranhão (Paraíso, 1987).

$\mathrm{Na}$ Terra Indígena (TI) Xakriabá estudada foram recenseados, em junho/ julho de 2003, uma população indígena de 6.442 pessoas. Nesta terra, há 52 localidades, subdivididas em 27 aldeias e 25 sub-aldeias, com 1.224 casas ocupadas, distribuídas esparsamente em duas áreas contíguas que têm, respectivamente, 46.415 e 6.660 ha (Schettino et al, 1999). A área maior foi delimitada em 1978 e demarcada em 1987, e a outra, ainda não demarcada, foi identificada e delimitada somente em 1999. De um modo geral, a ocupação dessas áreas está limitada pela pouca disponibilidade de água e se restringe, basicamente, aos pontos onde esta é mais abundante. É preferencialmente em torno desses espaços, onde há olhos d'água ou cursos perenes, que se organizam aldeias ou agrupamentos de aldeias, chamados de sub-aldeias.

O povo Xakriabá foi contatado em período bem remoto da colonização do Brasil, ao tempo em que se deu a ocupação do alto-médio vale do rio São Francisco. De tal sorte, fortes impactos ocorreram sobre sua organização social durante esse contato ao longo dos séculos. Contudo, demonstrando grande resistência, conseguiram manter sua base territorial na região.

Considerando a ainda reduzida compreensão das particularidades da população indígena brasileira sobre seu comportamento e seus hábitos sanitários e a associação destes com seu estado e sua dinâmica de saúde, desenvolveu-se o presente estudo junto à importante população Xakriabá. Ademais, se nas populações com características dominantes ainda persistem lacunas de entendimento sobre a relação entre o saneamento e a saúde (Heller, 1997), nessas populações tradicionais tal aprofundamento mostra-se ainda mais necessário, dadas suas características específicas.

Diante disso, no estudo integrante deste artigo, investigou-se a situação do abastecimento de água e do esgotamento sanitário; o quadro de saúde e a associação ecológica entre a mudança ou a prevalência do nível de exposição à carência dos serviços e indicadores de saúde, na população infantil indígena Xakriabá.

\section{MÉTODOS}

\section{Procedimento adotado para ingresso na Terra Indígena}

Por se tratar de estudo realizado em Terra Indígena e que abordou a área temática saúde, a presente pesquisa seguiu as diretrizes da Instrução Normativa no 01/PRES, de 29/11/95, da Fundação Nacional do Índio - FUNAI, que disciplinam o ingresso em terras indígenas com finalidade de desenvolver pesquisa científica, e as determinaçôes da Resolução no 196/96, do Conselho Nacional de Saúde. Assim, a pesquisa foi aprovada pelo CNPq (Parecer CA - AM 05/02) e pelos Comitês de Ética em Pesquisa (Parecer COEP no 138/02; Parecer CONEP nº 1581/2002).

O núcleo da pesquisa foi o levantamento de dados realizado através de trabalho de campo específico, o qual foi desenvolvido durante os meses de fevereiro a agosto de 2003, de forma descontinua.

\section{Definição dos indicadores de morbidade infantil}

Como a FUNASA passou a atuar sistematicamente na TI Xakriabá no ano de 2000, os dados de morbidade infantil abrangeram o período de janeiro de 2000 a dezembro de 2002. Os dados foram obtidos por meio da busca dos resultados de consultas a que as crianças indígenas se submeteram e que são mantidos nos prontuários dos estabelecimentos de saúde localizados na própria Terra Indígena, nos postos de saúde instalados nas aldeias Brejo Mata Fome, Rancharia e Sumaré.

Como são nos períodos pós-neonatal (crianças com 29 dias e menos de um ano) e pré-escolar (crianças com um ano e menos de cinco anos) que predominam as doenças advindas do contato entre a criança e seu meio ambiente, e levando em consideração as normas promovidas pela Organização Mundial de Saúde - OMS, que sugerem o aleitamento materno, excluindose até mesmo água suplementar e chás, até a criança completar no mínimo quatro meses de idade (Correia et al, 1999), foi definido como grupo etário de interesse aquele que envolve crianças com idade entre quatro meses e cinco anos incompletos, residentes na TI Xakriabá.
Ocorrências de diarréia, doenças infecciosas de pele e parasitoses intestinais, diagnosticadas pelas equipes de saúde que atuaram e atuam na TI Xakriabá durante os anos de 2000 a 2002, foram incluídas no estudo, tendo como parâmetro a classificação ambiental de agravos à saúde relacionados à água e aos esgotos realizada por Mara e Feachem (1999), além de ser recorrente na literatura que as doenças infecciosas e parasitárias fazem parte da rotina diária das famílias das classes populares brasileiras e das sociedades indígenas (Vieira, 2003; Teixeira, 2003; FUNASA, 2003; Azevedo, 2003; Vasconcelos, 1997; Heller, 1995).

Após a classificação dos diagnósticos, foram calculados, para cada um dos anos contemplados pela pesquisa, $o$ coeficiente de incidência, para os casos de diarréia e de doenças infecciosas de pele, e o coeficiente de prevalência para os casos de doenças parasitárias. É importante destacar, os episódios de diarréia e de doenças infecciosas de pele, quando relacionados ao mesmo indivíduo, foram considerados como "casos novos", quando o diagnóstico era intercalado por mais de, respectivamente, 15 e 30 dias.

A estimativa da população, para efeito da determinação dos denominadores, foi realizada por meio de técnica direta, baseada no acompanhamento anual das geraçôes, por sexo, considerando a população recenseada no ano de 2003 como população de referência, distribuída por idades simples e sexo. Depois de quantificados os nascimentos e óbitos, por idade, sexo e ano de ocorrência do evento, procedeu-se à reconstrução da população para cada ano do período 2000-2002. À população do início do segundo semestre de 2003 foram acrescentados os óbitos e extraídos os nascimentos dos semestres anteriores, obtendo-se assim os efetivos da população em cada ano, também por idades simples e sexo, para todo o período analisado. Tanto as idades dos sobreviventes quanto dos nascimentos e dos óbitos foram ajustadas para o dia primeiro de julho, sendo a população estimada para cada ano considerada a população média destes anos, conforme sugere Pagliaro (2002).

Foi adotada, para cada ano em particular, a população infantil nascida nos intervalos de tempo apresentados na Tabela 1. Estas datas de nascimento foram definidas em função do grupo 
etário de interesse. Para os limites inferiores e superiores, quando a data de nascimento das crianças não foi informada, optou-se por excluí-las do estudo.

\section{Definição dos estados de exposição e de não-exposição}

Com a finalidade de descrever a população Xakriabá e as condições sanitárias de suas moradias, foi desenvolvida uma "pesquisa de survey". Em assim sendo, foi elaborado um questionário, denominado inquérito domiciliar, parcialmente estruturado, no qual foi solicitado aos respondentes escolher uma alternativa numa lista apresentada pelo entrevistador.

A equipe de trabalho foi composta por 13 entrevistadores - todos agentes indígenas de saúde - e dois supervisores de campo, servidores da FUNASA de nível médio, com experiência anterior em trabalhos de campo no âmbito da própria FUNASA. Houve treinamento prévio dos entrevistadores e a supervisão dos trabalhos foi realizada pelo primeiro autor deste artigo.

A realização das entrevistas domiciliares iniciou-se no dia 11 de junho de 2003 e foi finalizada no dia 31 de julho de 2003, contemplando as 1.224 habitações ocupadas àquela época.

Todos os questionários foram revisados e as perguntas codificadas para facilitar a digitação. Posteriormente, os dados foram digitados numa interface desenvolvida para a digitação dos inquéritos domiciliares, utilizando o aplicativo Microsoft Access 97. A consistência do banco de dados foi verificada analisando a distribuição de freqüência para cada variável utilizada e fazendo o cruzamento de variáveis que tinham algum tipo de relação.

Os estados de exposição e de não exposição foram definidos, respectivamente, como ausência ou deficiência da infra-estrutura de saneamento e existência de adequados serviços de saneamento. A infra-estrutura de saneamento, para cada ano do estudo, foi levantada a partir dos inquéritos domiciliares e dos relatórios elaborados pela Divisão de Engenharia e Saúde Pública da Coordenação Regional da FUNASA em Minas Gerais. Quando não informada a data de implantação da melhoria sanitária em uma determinada localidade, ela foi considerada como ausente.

Tabela I - Período de tempo do denominador utilizado para os anos de 2000 a 2002

\begin{tabular}{cc}
\hline Ano & Data de nascimento da população estudada \\
\hline 2000 & $30 / 06 / 1995$ a $28 / 02 / 2000$ \\
2001 & $30 / 06 / 1996$ a $28 / 02 / 2001$ \\
2002 & $30 / 06 / 1997$ a 28/02/2002 \\
\hline
\end{tabular}

A fim de proceder à avaliação da qualidade da água, foi solicitada à Fundação Nacional de Saúde FUNASA, Coordenação Regional de Minas Gerais, a análise microbiológica e físico-química da água de beber consumida pelos Xakriabá em suas habitaçôes, bem como do manancial responsável pelo seu abastecimento. Foi entregue à Unidade Regional de Controle da Qualidade da Água da FUNASA uma relação de quatro a seis casas por aldeia e sub-aldeia, selecionadas por sorteio, onde morava pelo menos uma criança de zero a oito anos de idade, e solicitado que fosse realizada a coleta e análise da água em pelo menos dois domicílios, no local onde a água usada para beber estivesse armazenada. As análises foram realizadas nos meses de outubro a dezembro de 2003, seguindo as metodologias recomendadas pelo Standard Methods (1998).

\section{Estratégia epidemiológica e analítica}

O delineamento epidemiológico empregado foi o estudo ecológico, assumido como o delineamento em que "a unidade de análise não é constituída de indivíduos, mas de grupos de indivíduos" (Almeida Filho et al, 2002; Pereira, 2000). Neste caso, a investigação epidemiológica tomou como unidade de observação e análise os grupos de indivíduos residentes nas localidades utilizadas como referência pelo setor biomédico. Para tanto, lançou-se mão dos dados de morbidade e dos estados de exposição conforme definidos anteriormente.

No processo de análise dos dados do estudo ecológico foram empregados: análise gráfica simples e análise de correlação por postos, com a determinação do coeficiente de correlação por postos de Spearman e do teste de significância, utilizando o software SPSS 11.5 (Statistical Package for Social Science).

\section{RESULTADOS E DISCUSSÃO}

\section{Condições de saneamento}

No período de atuação da FUNASA na TI Xakriabá, de 2000 até julho de 2003, data de encerramento dos inquéritos domiciliares, a infraestrutura de saneamento apresentou melhorias em relação ao abastecimento de água. Entretanto, os avanços alcançados na prestação de serviços de rede geral de abastecimento de água não foram suficientes para diminuir as desigualdades existentes nos domicílios da sociedade Xakriabá no acesso às condições adequadas, sobretudo se forem comparadas com os moradores de domicílios localizados nas cidades brasileiras.

No Brasil, 82\% dos domicílios têm canalização em pelo menos um cômodo do domicílio ou a canalização está instalada até a propriedade. $\mathrm{Na}$ regiāo Sudeste, a abrangência das moradias atendidas por rede geral de abastecimento de água é de 91\% (IBGE, 2003). Na Terra Indígena em questão, a proporção de domicílios ligados à rede $(50,2 \%)$ era, respectivamente, 31,8 e 40,8 pontos percentuais inferior à proporção de domicílios brasileiros e da região Sudeste com rede de abastecimento de água. É interessante pôr em destaque que apenas $50,5 \% \mathrm{da}$ população Xakriabá (aproximadamente 3.255 indivíduos) era abastecida por rede e desta, no período analisado, somente 3,9\% tinham água clorada. Além disso, nem mesmo os domicílios que contavam com abastecimento de água tinham água em quantidade suficiente para o consumo de seus moradores.

Fato que também causa desconforto é saber que dentre as 108 habitações (8,8\% do total de domicílios ocupados) escolhidas aleatoriamente para ser realizada a análise da água consumida para beber, apenas 24 dos pontos amostrados $(22,2 \%)$ apresentaram ausência de coliformes totais e Escherichia coli. Em 
relação às outras amostras coletadas, foram observadas as seguintes situaçóes: 52 dos recipientes pesquisados $(48,2 \%)$ exibiram a presença de coliformes totais e os outros 32 restantes $(29,6 \%)$ mostraram resultados positivos para coliformes totais e Escherichia coli. Além disso, entre as amostras coletadas nas moradias cuja água é oriunda de poços tubulares profundos, $83,3 \%$ mostraram que a água era imprópria para o consumo humano. Na mesma medida que este cenário ilustra a qualidade da água ingerida pelos Xakriabá, também sugere que a qualidade de vida e a manutenção da saúde deste povo estavam sob risco.

Das condições de saneamento, a fim de se atingir um nível adequado que possa garantir melhorias nas condições de moradia e saúde da população, bem como preservar a qualidade do meio ambiente, o esgotamento sanitário é aquele que apresenta o mais longo caminho a ser percorrido. Esta situação torna-se mais evidente ao se verificar a proporção de domicílios que não dispunha de instalaçôes sanitárias na TI Xakriabá: 77,5\%. Além disso, não se pode perder de vista que esta proporção sobe para $80,5 \%$ se for considerado o número de habitações que possuía instalações sanitárias e que estas não eram utilizadas, por motivos diversos (a falta de água em 28 domicílios e a resistência à nova tecnologia em outros sete), pelos seus moradores (13,8\%). Já a proporção de domicílios com o aparelho sanitário ligado à fossa séptica $(11,8 \%)$ aproximava-se do valor de $12,9 \%$ encontrado no Censo Demográfico de 2000 (IBGE, 2001) para o conjunto dos domicílios das áreas rurais do País. Mesmo levando em consideração os 145 módulos sanitários construídos nos domicílios desse povo até julho de 2003 e admitindo, por hipótese, que novas casas não foram levantadas nesse ínterim, ainda assim a proporção de $11,8 \%$ está muito aquém do necessário.

\section{Indicadores de saúde e fatores de exposição relacionados à carência de saneamento}

$\mathrm{Na}$ presente pesquisa foram utilizados três indicadores de saúde (casos de diarréia, casos de doenças infecciosas de pele e casos de doenças parasitárias) e dois fatores de exposição (crianças sem acesso à água de poços tubulares profundos através de rede geral em seus domicílios e chafarizes; crianças cujas habitações não possuíam ou os seus moradores não utilizavam as instalações sanitárias) para os anos de 2000, 2001 e 2002.

Na Tabela 2 estão detalhados os indicadores de saúde para cada uma das localidades. Vale destacar, as maiores taxas de incidência e prevalência foram encontradas para o ano de 2001. Por exemplo, a taxa de incidência de diarréia alcançou 809, 52 casos por 1.000 crianças, no ano de 2001 na aldeia Riachão, e a prevalência de doenças parasitárias na aldeia Sapé foi de 583,33 casos por mil no mesmo ano.

Em relação às variáveis de exposição, observa-se que, de 2000 para 2001 e de 2001 para 2002, ocorreu uma redução, respectivamente, de 11,8 e 37,5 pontos percentuais na proporção de crianças expostas a uma água de pior qualidade e de 3,7 e 8,7\% em relação à ausência de instalaçôes sanitárias (Tabela 3).

Dentre os três indicadores de saúde abordados, merecem realce os casos de diarréia. Coimbra Júnior (2007) afirma que "a diarréia destaca-se dentre as principais causas de adoecimento e morte da criança indígena, seguida pela pneumonia (ambas podem responder por 60 a $80 \%$ das causas de internação, segundo algumas análises)". Os estudos realizados com os povos Suruí, Rondônia (Orellana et al, 2007), Guarani Kaiowá e Nandéva, Mato Grosso do Sul (Pícoli et al, 2006); Terena, Mato Grosso do Sul (Ribas et al, 2001) e Kulina, Amazonas (Tiss et al, s.d) corroboram esta assertiva.

Conforme expressa a Tabela 4, na TI Xakriabá as diarréias acometem em maior proporção as crianças menores de um ano, reiterando a vulnerabilidade dessa faixa etária.

Como mencionado por Silva (2002), os coeficientes de incidência de doenças diarréicas na população indígena brasileira para os anos de 2000, 2001 e até junho de 2002 são: 95,2; 245,8 e 184,54 (por mil habitantes). À exceção do índice achado para o ano de 2001, praticamente equivalente, os outros dois coeficientes atingiram valores mais elevados do que os encontrados para a população infantil total da TI Xakriabá (Tabela 2). Observando a evolução temporal dos dados, e considerando-se que os dados de 2000 possivelmente carreguem significativa sub-notificação, conforme discutido na seção seguinte, percebe-se uma tendência da redução dos episódios de diarréia. Tal tendência pode resultar do aumento do número de equipes multidisciplinares na atenção à saúde da população indígena, o que teria propiciado maior cobertura assistencial e disseminação de informações sobre prevenção de doenças, assim como de investimentos em saneamento básico.

\section{Associações}

Pode-se observar na Tabela 5 que, utilizando-se o método de inferência estatística não-paramétrico, há evidência da existência de correlação entre a prevalência de doenças parasitárias e a proporção de crianças sem instalações sanitárias nos domicílios para o ano de 2001 e entre a incidência de doenças infecciosas de pele e a proporção de crianças sem instalaçóes sanitárias nos domicílios para o ano de 2002. As estatísticas amostrais (coeficientes de correlação por postos de Spearman - r), 0,389 e-0,406, respectivamente, aproxima e excede dos valores críticos \pm 0,392 (valor retirado da Tabela A-9, "Valores Críticos do Coeficiente de Correlação por Postos r, de Spearman", Triola, 1998), mostrando que há uma correlação positiva entre o indicador de saúde PDP e o fator de exposição PCSISD e uma correlação negativa entre o indicador de saúde IDIP e o fator de exposição PCSISD, para o nível de 0,05 de significância. Diante disso, pode-se inferir que a ausência de instalações sanitárias nos domicílios parece favorecer a maior prevalência de doenças parasitárias. No caso específico de incidência de doenças infecciosas de pele, o resultado parece mostrar que a ausência de instalaçôes sanitárias no domicílio estaria funcionando como um "fator de proteção" para a incidência de doenças de pele entre os indígenas, o que seria difícil, epidemiologicamente, ser explicado. Vale lembrar que as instalaçôes sanitárias, usualmente, são compostas por vaso sanitário, pia e chuveiro, o local adequado para a prática de alguns hábitos de higiene.

Possivelmente, as hipóteses para o pouco número de correlações significantes entre as variáveis estudadas estejam relacionadas a vários fatores, a saber:

- a variável de exposição PCSAP pode não ser representativa, uma vez 


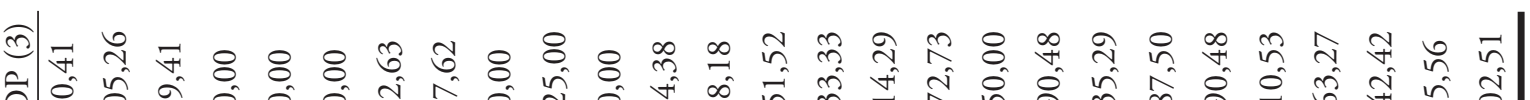

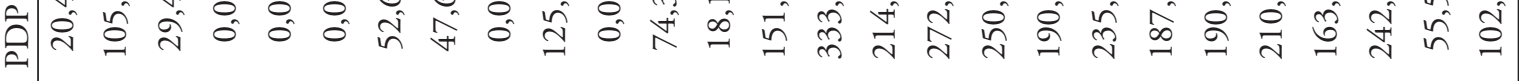

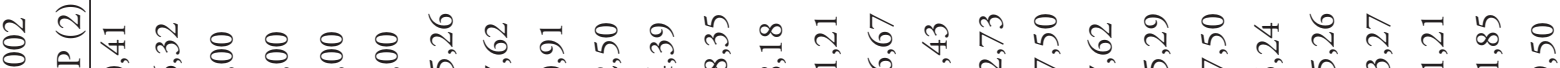

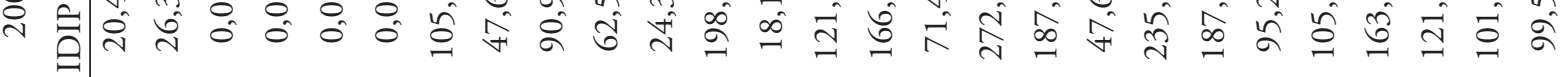

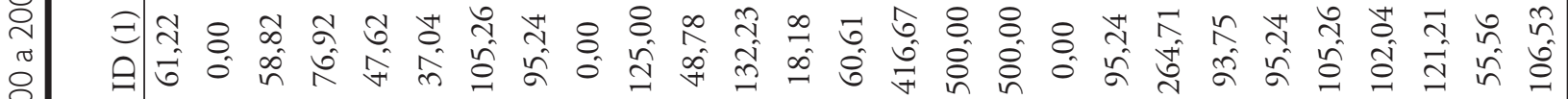

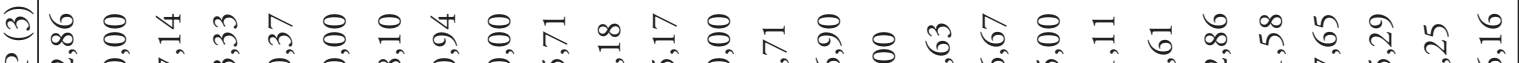

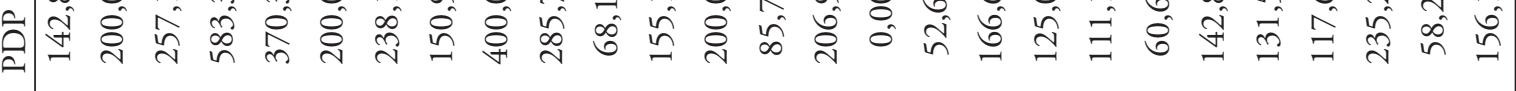

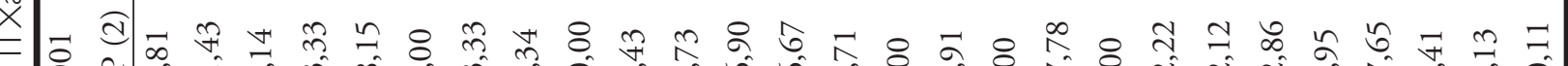

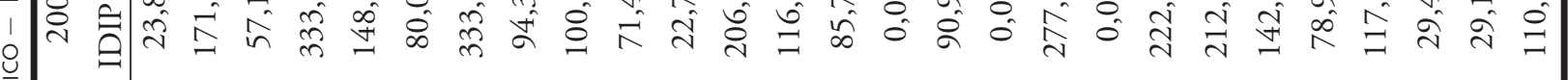
छ

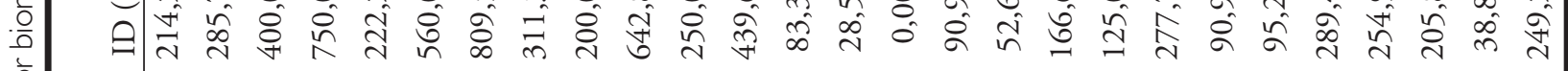

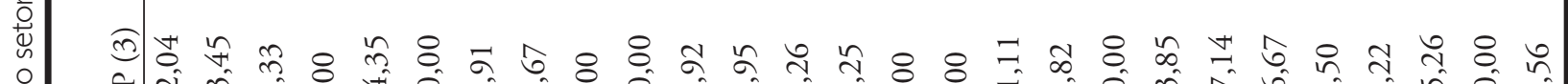

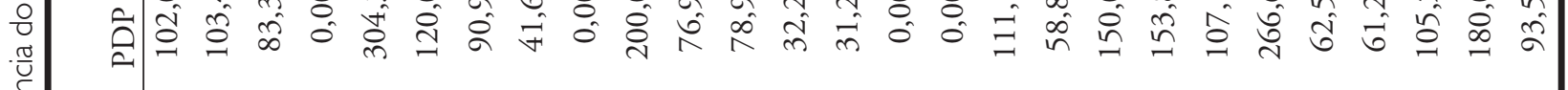

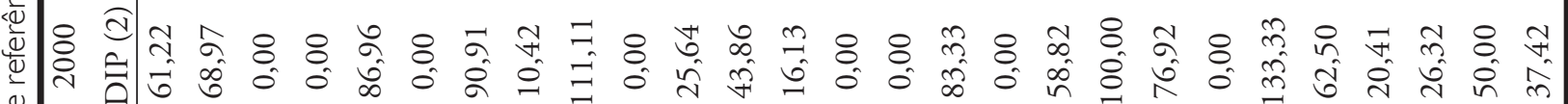

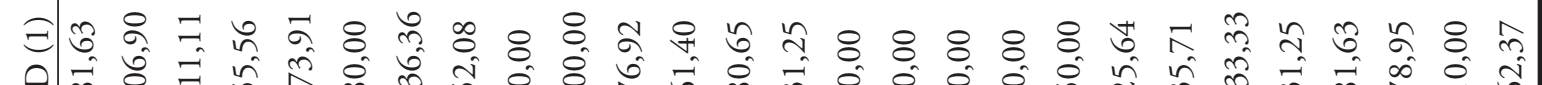

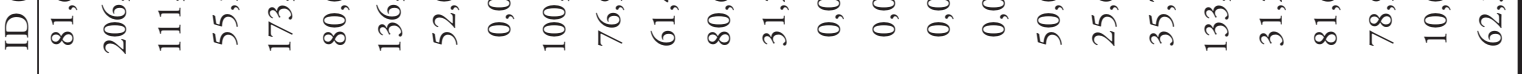

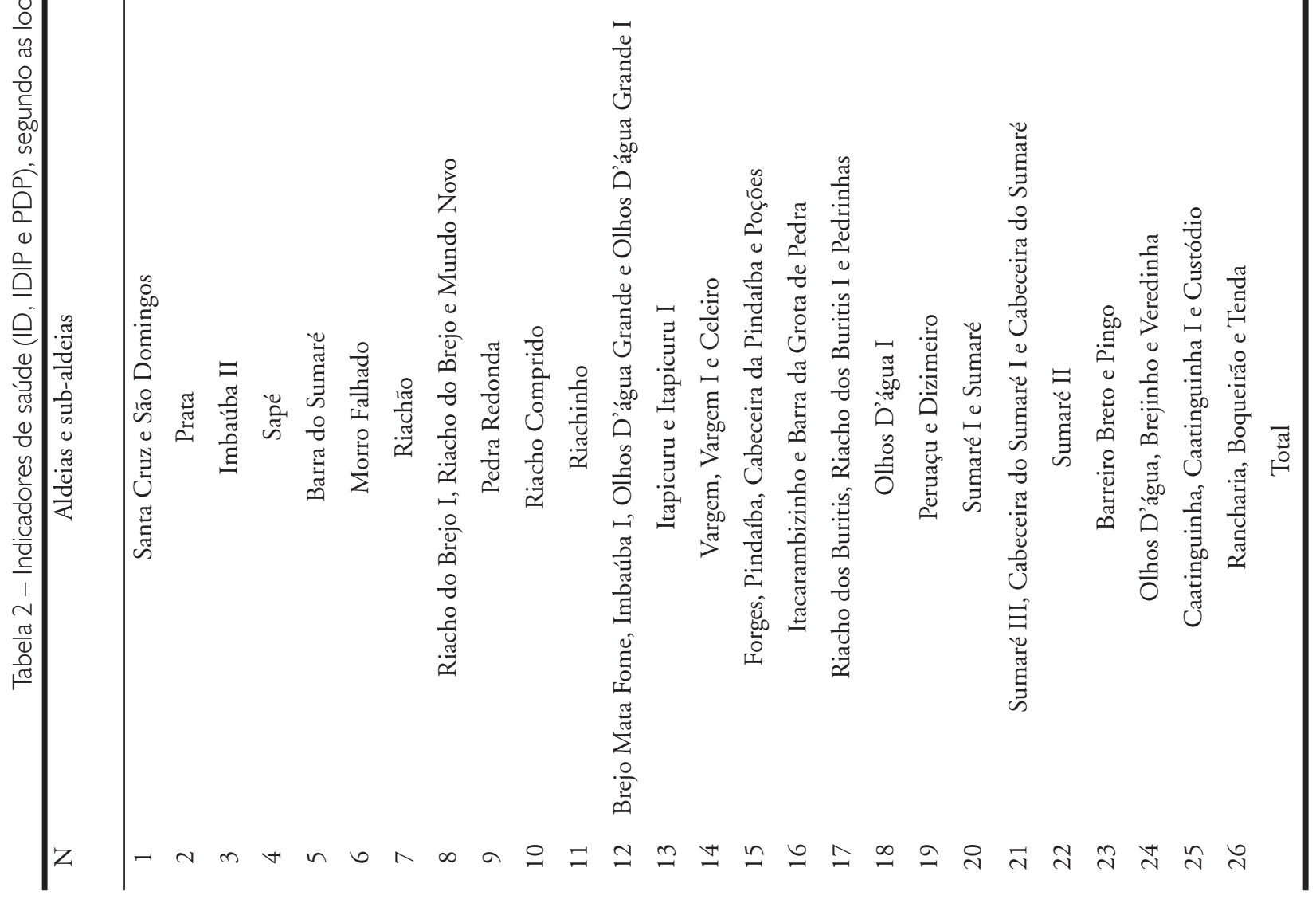

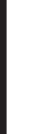

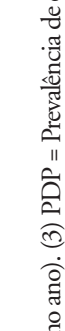
. 
Tabela 3 - Fatores de exposição (PCSAP e PCSISD), segundo as localidades de referência do setor biomédico - TI Xakriabá, 2000 a 2002

\begin{tabular}{|c|c|c|c|c|c|c|c|}
\hline \multirow[t]{2}{*}{$\mathrm{N}$} & \multirow{2}{*}{$\begin{array}{l}\text { Aldeias e } \\
\text { sub-aldeias }\end{array}$} & \multicolumn{2}{|c|}{2000} & \multicolumn{2}{|c|}{2001} & \multicolumn{2}{|c|}{2002} \\
\hline & & $\begin{array}{l}\text { PCSAP } \\
(1) \\
\end{array}$ & $\begin{array}{l}\text { PCSISD } \\
(2)\end{array}$ & $\begin{array}{l}\text { PCSAP } \\
(1)\end{array}$ & $\begin{array}{l}\text { PCSISD } \\
(2)\end{array}$ & $\begin{array}{l}\text { PCSAP } \\
(1)\end{array}$ & $\begin{array}{c}\text { PCSISD } \\
(2)\end{array}$ \\
\hline 1 & Santa Cruz e São Domingos & 71,43 & 100,00 & 71,43 & 100,00 & 73,47 & 100,00 \\
\hline 2 & Prata & 100,00 & 100,00 & 100,00 & 100,00 & 100,00 & 100,00 \\
\hline 3 & Imbaúba II & 100,00 & 100,00 & 100,00 & 100,00 & 11,76 & 100,00 \\
\hline 4 & Sapé & 0,00 & 100,00 & 0,00 & 100,00 & 0,00 & 100,00 \\
\hline 5 & Barra do Sumaré & 100,00 & 100,00 & 100,00 & 100,00 & 100,00 & 100,00 \\
\hline 6 & Morro Falhado & 100,00 & 100,00 & 100,00 & 100,00 & 0,00 & 100,00 \\
\hline 7 & Riachão & 100,00 & 100,00 & 100,00 & 100,00 & 100,00 & 100,00 \\
\hline 8 & $\begin{array}{l}\text { Riacho do Brejo I, Riacho do Brejo e } \\
\text { Mundo Novo }\end{array}$ & 95,83 & 100,00 & 66,04 & 100,00 & 63,81 & 96,19 \\
\hline 9 & Pedra Redonda & 0,00 & 100,00 & 0,00 & 100,00 & 0,00 & 9,09 \\
\hline 10 & Riacho Comprido & 100,00 & 100,00 & 100,00 & 100,00 & 0,00 & 100,00 \\
\hline 11 & Riachinho & 100,00 & 100,00 & 100,00 & 100,00 & 17,07 & 100,00 \\
\hline 12 & $\begin{array}{c}\text { Brejo Mata Fome, Imbaúba I, Olhos D’água } \\
\text { Grande e ODG I }\end{array}$ & 50,00 & 93,86 & 51,72 & 67,24 & 28,10 & 60,33 \\
\hline 13 & Itapicuru e Itapicuru I & 100,00 & 100,00 & 100,00 & 100,00 & 100,00 & 100,00 \\
\hline 14 & Vargem, Vargem I e Celeiro & 100,00 & 100,00 & 60,00 & 100,00 & 60,61 & 100,00 \\
\hline 15 & $\begin{array}{c}\text { Forges, Pindaíba, Cabeceira da Pindaíba e } \\
\text { Poçōes }\end{array}$ & 76,67 & 100,00 & 79,31 & 100,00 & 79,17 & 100,00 \\
\hline 16 & Itacarambizinho e Barra da Grota de Pedra & 100,00 & 100,00 & 100,00 & 100,00 & 100,00 & 100,00 \\
\hline 17 & $\begin{array}{c}\text { Riacho dos Buritis, Riacho dos Buritis I e } \\
\text { Pedrinhas }\end{array}$ & 55,56 & 88,89 & 36,84 & 94,74 & 36,36 & 100,00 \\
\hline 18 & Olhos D’água I & 100,00 & 100,00 & 100,00 & 100,00 & 100,00 & 93,75 \\
\hline 19 & Peruaçu e Dizimeiro & 100,00 & 100,00 & 100,00 & 100,00 & 100,00 & 100,00 \\
\hline 20 & Sumaré I e Sumaré & 38,46 & 100,00 & 38,89 & 100,00 & 0,00 & 38,24 \\
\hline 21 & $\begin{array}{l}\text { Sumaré III, Cabeceira do Sumaré I e Cabeceira } \\
\text { do Sumaré }\end{array}$ & 100,00 & 100,00 & 0,00 & 100,00 & 0,00 & 100,00 \\
\hline 22 & Sumaré II & 0,00 & 100,00 & 0,00 & 100,00 & 0,00 & 33,33 \\
\hline 23 & Barreiro Breto e Pingo & 6,25 & 96,88 & 5,26 & 97,37 & 2,63 & 92,11 \\
\hline 24 & Olhos D’água, Brejinho e Veredinha & 93,88 & 100,00 & 96,08 & 98,04 & 97,96 & 95,92 \\
\hline 25 & Caatinguinha, Caatinguinha I e Custódio & 15,79 & 100,00 & 14,71 & 100,00 & 12,12 & 100,00 \\
\hline \multirow[t]{2}{*}{26} & Rancharia, Boqueirão e Tenda & 4,00 & 75,00 & 3,88 & 70,87 & 1,85 & 61,11 \\
\hline & Total & 67,05 & 96,36 & 59,96 & 92,89 & 43,62 & 85,43 \\
\hline
\end{tabular}

(1) PCSAP = Proporção de crianças sem acesso à água de poços tubulares profundos (\%).

(2) PCSISD = Proporção de crianças sem instalações sanitárias nos domicílios (\%). 
Tabela 4 - Incidência de diarréia por faixa etária (novos casos por mil crianças.ano) - TI Xakriabá, 2000 a 2002

\begin{tabular}{ccc}
\hline Faixa Etária & 4 meses a 1 ano & 1 a 5 anos \\
\hline ID 2000 & 186,67 & 39,41 \\
ID 2001 & 788,73 & 159,86 \\
ID 2002 & 341,27 & 72,50 \\
\hline
\end{tabular}

Tabela 5 - Associação entre os indicadores de saúde (ID, IDIP e PDP) e os fatores de exposição (PCSAP e PCSISD) - teste não-paramétrico $(N=26)$

\begin{tabular}{cc}
\hline Indicador de saúde x fator & $\begin{array}{c}\text { Coeficiente de correlação } \\
\text { de exposição }\end{array}$ \\
\hline ID2000 x PCSAP2000 de Spearman $(\mathrm{r})$
\end{tabular}

\section{Notas:}

ID = Incidência de diarréia (casos novos por mil crianças, no ano).

IDIP = Incidência de doenças infecciosas de pele (casos novos por mil crianças, no ano).

$\mathrm{PDP}=$ Prevalência de doenças parasitárias (casos existentes por mil).

PCSAP = Proporção de crianças sem acesso à água de poços profundos (\%).

PCSISD = Proporção de crianças sem instalaçôes sanitárias nos domicílios (\%).

que as análises microbiológicas da água dos potes e filtros de vela indicaram que, independentemente da origem da água, nestes locais há uma proporção muito grande de presença de coliformes totais, inclusive Escherichia coli;

- as perdas nas consultas, bem como as sub-notificaçôes, podem ter influenciado os valores obtidos para os indicadores de saúde, principalmente nas localidades onde a incidência ou prevalência foi nula;

- certamente, variáveis de exposição relacionadas aos hábitos de higiene seriam mais indicadas para esta análise.
Entretanto, constatou-se, na aplicação dos inquéritos domiciliares, que variáveis relativas a este tema tendem a apresentar baixa confiabilidade. Foram identificadas, por meio da observação direta, respostas dadas pelos entrevistados que não condizem com as práticas do dia-a-dia da população Xakriabá. Além disso, para este estudo, em termos cronológicos, não seria possível quantificar estas variáveis.

Além dos resultados obtidos na análise estatística por meio de método não-paramétrico, indicando uma provável relação entre alguns indicadores de saúde e um dos fatores de exposição estudados, as Figuras 1 a 3 sugerem que as açôes de saneamento estão associadas à redução da morbidade infantil, principalmente se for considerado que os valores indicados para o ano de 2000 tendem a ser superiores aos encontrados nesta pesquisa.

A atuação da FUNASA na TI Xakriabá é recente. As equipes de saúde foram contratadas a partir de 2000 e as intervençôes sanitárias foram iniciadas efetivamente em 2001. Por conseguinte, a série temporal estudada é reduzida e, além disso, os dados de morbidade infantil observados para o ano de 2000 não representam a realidade dos fatos, devendo envolver significativo grau de sub-notificação, sendo portanto subestimados.

$\mathrm{Na}$ Figura 1, incidência de diarréia versus porcentagem de população infantil abastecida com rede geral e chafarizes, os resultados mostram a relação entre essas variáveis, no período de 2001 a 2002, o que está de acordo com os conhecimentos do efeito relativo das açôes de saneamento sobre esse indicador de saúde. Semelhante resultado observa-se na Figura 2, prevalência de doenças parasitárias confrontadas com a porcentagem da população infantil atendida com instalaçôes sanitárias.

As doenças parasitárias e infecciosas de pele, expressas nas Figuras 2 e 3, também estão relacionadas aos fatores comportamentais (hábitos de higiene, por exemplo) e ambientais (domínio público e domínio privado). Por meio da observação direta, pôde-se verificar com atenção que, normalmente, os pais banham as suas crianças entre o meiodia e as 14 horas, período em que o sol está alto. Após o banho, as crianças sujam-se novamente e é desta maneira que adormecem. Cabe observar que, dos 1.224 domicílios recenseados em 2003 na Terra Indígena, 818 (66,83\%) não possuíam nenhum tipo de revestimento no piso, ou seja, eram de terra batida. O piso de terra, estando a terra solta, provoca poeira no ambiente doméstico, podendo trazer prejuízo para a saúde da população. De mais a mais, o piso de terra batida ou de tijolos dificulta a higiene doméstica, "uma das estratégias preventivas na transmissão de doenças feco-orais e das controladas pela limpeza com água" (Heller e Möller, 1995:59).

$\mathrm{Na}$ Figura 3, as variáveis levadas em consideração são a incidência de 


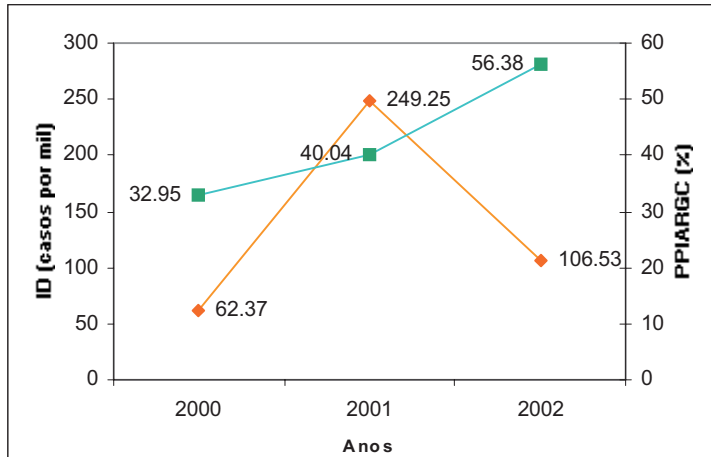

- Incidência de diarréia (casos por mil)

- Porcentagem da população infantil abastecida com rede geral e chafarizes

Figura I - Morbidade por diarréia x população infantil abastecida com sistema coletivo de água - TI Xakriabá, 2000 a 2002

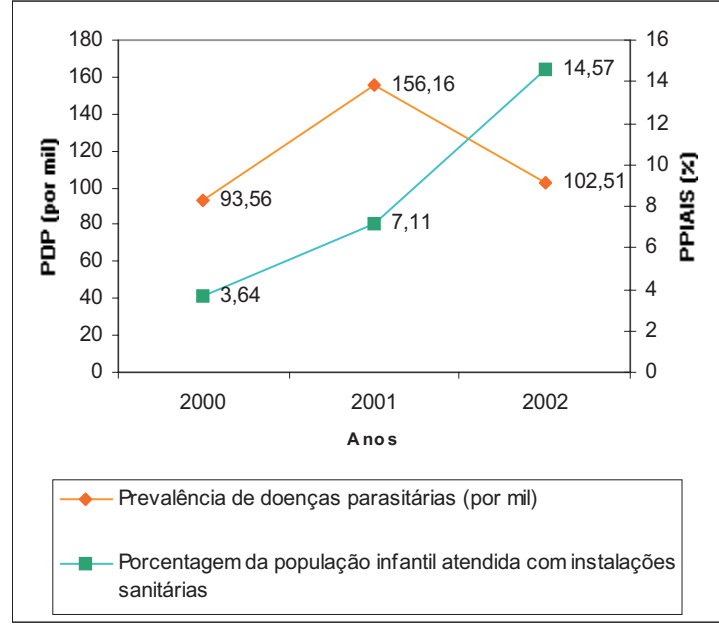

Figura 2 - Morbidade por doenças parasitárias $x$ população infantil atendida com tecnologia adequada para disposição dos dejetos - TI Xakriabá, 2000 a 2002

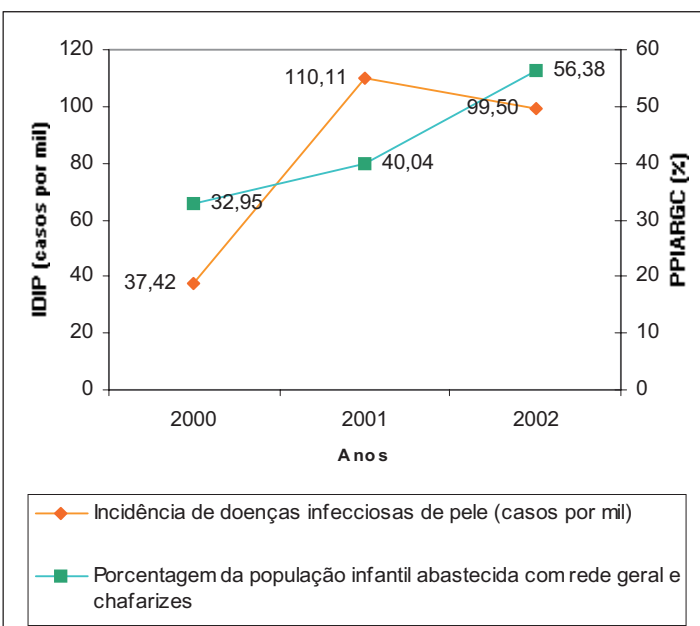

Figura 3 - Morbidade por doenças infecciosas de pele x População infantil abastecida com rede geral e chafarizes - TI Xakriabá, 2000 a 2002 doenças infecciosas de pele e a porcentagem da população infantil abastecida com rede de água e chafarizes, podendose observar que há conexão em termos de diferencial entre a proporção de abastecimento de água de 2001 para 2002 e a incidência de doenças infecciosas de pele no mesmo período.

Uma análise crítica da metodologia empregada para quantificar as variáveis de exposição aponta para a possibilidade de viés de aferição em algum grau, pois os valores da proporção de crianças que não tinham acesso à água de poços tubulares profundos $\mathrm{e}$ a instalações sanitárias são referentes a um cenário identificado em 2003, pela aplicação dos inquéritos domiciliares, e correlacionados com as informaçōes obtidas sobre a data de implantação das melhorias sanitárias nas aldeias e sub-aldeias. Em outras palavras, não foram levadas em consideração as migrações internas e externas da população Xakriabá, que provavelmente ocorreram no período de 2000 a 2002. Assim, os dados de exposição à época da doença podem ser diferentes daqueles utilizados no estudo.

Outra limitação inerente a este tipo de estudo diz respeito ao fato de que qualquer fator de exposição apresenta um tempo mínimo de latência para que seus efeitos possam ser observados. Sendo assim, ao reconhecer que se trata de área em que mudanças estavam em implementação no período, a avaliação da ocorrência dos desfechos, entre 2000 a 2002, pode ter ficado prejudicada.

\section{CONSIDERAÇÕES FINAIS}

A dominação e a marginalização experimentada pela população indígena brasileira ao longo de sua história associam-se, no povo Xakriabá, à perda de território e mudanças ambientais que, por sua vez, vêem resultando no abandono das técnicas tradicionais de subsistência, na alteração da forma tradicional de ocupação do território, na conversão ao sedentarismo e em maiores concentrações demográficas em suas aldeias. Estes são alguns dos fatores que vêem contribuindo para uma situação de saúde precária daquele povo, sobretudo de suas crianças.

Suas condições sanitárias em geral não são satisfatórias, o que vem possivelmente determinando elevada prevalência de doenças endêmicas como 
a verminose, altas taxas de incidência de diarréia e doenças infecciosas de pele.

A pesquisa desenvolvida, associada a observações posteriores acerca da atuação do Estado no campo da saúde indígena, permite algumas inferências sobre o problema.

Apesar de a FUNASA, por meio do Distrito Sanitário Especial Indígena de Minas Gerais e Espírito Santo (DSEI-MG/ES), estar atuando na TI Xakriabá, os serviços de saúde disponibilizados àquela população ainda não se mostraram capazes de contornar a situação frágil da saúde indígena. Observações quanto às dificuldades institucionais para atender as necessidades de saúde e de saneamento no período de 2000 a 2002, tanto pelo setor biomédico quanto pelo setor de saneamento, apontaram para deficiências da estrutura burocrático-administrativa, fragmentada e com pouco apoio da instituição; pouco clara definição de competências e responsabilidades no planejamento, execução, fiscalização e avaliação dos serviços de saúde; reduzido e inexperiente quadro de pessoal.

Sob esse último prisma, de modo geral os profissionais que atuam na esfera do saneamento dispóem de conhecimento restrito das diretrizes da política nacional de atenção à saúde dos povos indígenas, para promoção de ambientes saudáveis e proteção da sua saúde, e não foram qualificados para desenvolver atividades como a educação em saúde. De mais a mais, como grande parte dos outros profissionais que atuam na Terra Indígena, não se verificou capacitação específica para o trabalho intercultural. Em assim sendo, as intervençôes na área de saúde estão sendo realizadas sem o necessário conhecimento da cultura dos Xakriabá e o reconhecimento de como a especificidade cultural do grupo influencia o êxito do trabalho. Deve-se ter em mente que cada povo indígena é um caso, portanto há que se traçarem estratégias e práticas diferenciadas para desenvolver atividades com cada um deles.

De sua parte, as ações de saneamento desenvolvidas na TI Xakriabá não têm como base critérios epidemiológicos e não estão conseguindo universalizar para a população água em quantidade e de boa qualidade, além de destino final adequado aos dejetos por meio de módulos sanitários. Contudo, mesmo se constatando a atuação limitada e, por vezes, deficiente do setor de saneamento na Terra Indígena, os resultados encontrados neste estudo parecem corroborar a hipótese de Briscoe (1987), que indica serem os serviços de saneamento condiçōes necessárias, porém não suficientes para promover a melhoria da saúde.

\section{AGRADECIMENTOS}

Agradecemos ao CNPq - Conselho Nacional de Desenvolvimento Científico e Tecnológico pela concessão da bolsa de Mestrado ao primeiro autor deste artigo e à Fundação Nacional de Saúde, Coordenação Regional de Minas Gerais, por ter propiciado a realização da pesquisa de campo e as análises da água.

\section{REFERÊNCIAS}

ALMEIDA FILHO, N., ROUQUAYROL, M. Z. Introdução à epidemiologia. Rio de Janeiro: MEDSI Editora Médica e Científica Ltda, 2002.

AMERICAN PUBLIC HEALTH ASSOCIATION (APHA), AMERICAN WATER WORKS ASSOCIATION (AWWA), WATER ENVIRONMENT FEDERATION (WEF). Standard methods for the examination of water and wastewater. $20 \mathrm{ed}$. Washington, 1998

AZEVEDO, E. A. Exclusão sanitária em Belo Horizonte - MG: caracterização e associação com indicadores de saúde [Dissertação de Mestrado]. Belo Horizonte: Universidade Federal de Minas Gerais, 2003.

BRISCOE, J. Abastecimiento de agua y servicios de saneamiento: su función en la revolución de la supervivencia infantil. Boletim de la Oficina Sanitaria Panamericana; (103)4:325-39. 1987.

BRISCOE, J., FEACHEM, R. G. RAHAMAN, M. M. Evaluating health impact; water supply, sanitation and hygiene education. Ottawa: International Development Research Center, 1986

COIMBRA JÚNIOR, C. E. A. Aula inaugural do Curso de Vigilância Alimentar e Nutricional para Saúde Indígena. Disponivel na Internet via WWW. URL: http://www.ensp.fiocruz.br/biblioteca/dados/txt 346950656.ppt. Acesso em novembro de 2007.

CORREIA, L. L., MCAUlifFE, J. F. Saúde materno-infantil. In: ROUQUAYROL, M.Z.; ALMEIDA FILHO, N. Epidemiologia e saúde. 5ed. Rio de Janeiro: MEDSI Editora Médica e Científica Ltda, p.375-403, 1999.

FUNDAÇÃO NACIONAL DE SAÚDE (FUNASA). Relatório morbimortalidade 2002. Brasília: Funasa; 2003.

HELLER, L. Saneamento e saúde. Brasília: Organização Pan-Americana de Saúde - Representação do Brasil, 97 p. 1997.

HELLER, L. Associação entre cenários de saneamento e diarréia em Betim-MG: o emprego do delineamento epidemiológico caso-controle na definição de prioridades de intervenção [Tese].
Belo Horizonte: Universidade Federal de Minas Gerais, 1995.

HELLER, L., MÖLLER, L. M. Saneamento e saúde pública. In: BARROS, R. T. V.; CHERNICHARO, C. A. L.; HELLER, L.; von SPERLING, M. Manual de saneamento e proteção ambiental para os municípios. Belo Horizonte: Escola de Engenharia da UFMG, v.2, p.51-61, 1995.

INSTITUTO BRASILEIRO DE GEOGRAFIA E ESTATÍSTICA (IBGE). Pesquisa nacional por amostra de domicílios 2002 [CD-ROM]. Microdados. Rio de Janeiro: IBGE, 2003.

INSTITUTO BRASILEIRO DE GEOGRAFIA E ESTATÍSTICA (IBGE). Censo demográfico 2000. Características da populacão e dos domicílios: resultados do universo. Rio de Janeiro: IBGE, 1 CD-ROM encartado. 2001.

MARA, D. D., FEACHEM, R. G. Water and excreta-related diseases: unitary environmental classification. Journal of Environmental Engineering, v. 125 , n. 4 , p. 334-39, 1999.

MOTA, S. Saneamento. In: ROUQUAYROL, M. Z., ALMEIDA FILHO, N. Epidemiologia e saúde. Rio de Janeiro: MEDSI Editora Médica e Científica Ltda; p. 405-29. 1999.

ORELLANA, J. D. Y. et al. Morbidade hospitalar em crianças indigenas Suruí menores de dez anos, Rondônia, Brasil (2000 - 2004). Revista Brasileira de Saúde Materno Infantil, v. 7(3), p. 281-287, 2007.

PAGLIARO, H. A revolução demográfica dos povos indígenas do Brasil: a experiência dos Kaiabi do Parque Indígena do Xingu - Mato Grosso - 1970-1999. São Paulo: Departamento de Epidemiologia da Faculdade de Saúde Pública da Universidade de São Paulo. (Tese. Doutorado em Epidemiologia). 180 p. 2002.

PARAÍSO, M. H. B. Laudo antropológico. Identidade étnica dos Xakriabá [Relatório]. 1987.

PEREIRA, M. G. Epidemiologia: teoria e prática. Rio de Janeiro: Editora Guanabara Koogan S. A, 2000.

PÍCOLI, R., ADORNO, R. C. F. A saúde de crianças Kaiowá e Guarani: reflexóes. In: II Seminário Internacional: fronteiras da exclusão, 2006, Campo Grande. Anais... Campo Grande, 2006.

RIBAS, D. L. B. et al. Saúde e doença em crianças indígenas Terena. Cadernos de Saúde Coletiva, v. 9, n. 2, p. 139-154, 2001.

RODRIGUES, A. D. Linguas amerindias. Grande Enciclopédia Delta Larousse 1975; 9: 4035.

SCHETTINO M. P. F. et al. Relatório circunstanciado de identificação e delimitação da Terra Indígena Xakriabá Rancharia-MG [Relatório] 1999.

SILVA, V. T. Etnodesenvolvimento das sociedades indigenas. Disponivel na Internet via WWW. URL: http://www.abrasil.gov.br/avalppa/RelAvalPPA2002/content/av_prog/310/prog310.htm. Acesso em fevereiro de 2008.

TEIXEIRA, J. C. Associação entre cenários de saneamento e indicadores de saúde em crianças. Estudo em áreas de assentamento subnormal em Juiz de Fora-MG [Tese]. Belo Horizonte: Universidade Federal de Minas Gerais, 2003.

TISS, C., HERNANDES, I. C. Atendimento na Cidade versus Atendimento em Área - Um estudo 
Pena, J. L. \& Heller, L.

entre os Kulina nas terras indígenas do Médio Juruá e CacaulAmazonas/Brasil. [online] Disponivel na Internet via WWW. URL: http://www.comin. org.br/pub pesquisas.php. Acesso em fevereiro de 2008.

TRIOLA, M. F. Introdução à estatística. Rio de Janeiro: LTC - Livros Técnicos e Científicos Editora S.A, 1998.

VASCONCELOS, E. M. Educação popular como instrumento de reorientacão das estratégias de controle das doenças infecciosas e parasitárias [Tese]. Belo Horizonte: Universidade Federal de Minas Gerais, 1997.

VIEIRA, G. O. Enteroparasitoses em populaçōes indigenas no Brasil: uma revisão sistemática $d a$ produção científica [Dissertação de Mestrado]. Rio de Janeiro: Escola Nacional de Saúde Pública, Fundação Oswaldo Cruz; 2003.

Endereço para correspondência:

Léo Heller

Departamento de Engenharia

Sanitária e Ambiental da

Universidade Federal de Minas

Gerais

Av. do Contorno, 842 - $7^{\circ}$ Andar, CEP 3 I I I 0-060 Belo Horizonte

- MG - Brasil

Tel.: (3 I) 3409-1958

E-mail heller@desa.ufmg.br 